\title{
Embolization of Portosystemic Shunt for Treatment of Recurrent Hepatic Encephalopathy
}

\author{
Rajesh Gopalakrishna, Preetham S. Hurkadli, Nazar K. Puthukudy, Harikumar R. Nair \\ Department of Gastroenterology \& Hepatology, Amrita Institute of Medical Sciences, Kochi, Kerala 682041, India
}

\begin{abstract}
Hepatic encephalopathy in the setting of advanced chronic liver disease, occurs following a precipitating factor and generally responds to correction of the precipitating factor and anticoma measures. We report the case of a lady with Child A cirrhosis who presented with frequent episodes of hepatic encephalopathy without any precipitating factors. She was found to be having a large portosystemic shunt. The shunt was obliterated by coil embolotherapy following which there was no further episodes of encephalopathy. (J CuIN Exp HePATOL 2014;4:60-62)
\end{abstract}

A 36-year-old female was diagnosed to have liver cirrhosis since 2 years. She had multiple episodes of hepatic encephalopathy requiring frequent hospitalizations, which responded to lactulose and other anti-encephalopathy measures and supportive care. She never had any episode of hematemesis or melena.

General examination was unremarkable except for generalized hyperpigmentation. She did not have mucosal hyperpigmentation. Abdominal examination revealed mild splenomegaly. She had no stigmata of liver disease, KF ring, xanthalesma or other findings. On evaluation she was found to have Child class A liver functional status. Serum hepatitis B surface antigen and antibody against hepatitis $C$ virus was negative. Antibody against core antigen (total) was positive; however HBV DNA was undetectable on PCR quantification. Antinuclear antibody, antimitochondrial antibody, anti-smooth muscle antibody, antiphospholipid antibody $(\operatorname{IgG} \& \operatorname{IgM})$ were negative. Her serum ferrtin, and ceruloplasmin were within normal limits. She was non-diabetic and her lipid profile was within normal limits. Upper GI endoscopy did not reveal any varices and colonoscopy was also normal except for small hemorrhoids. Fasting arterial ammonia was $140 \mu \mathrm{mol} / \mathrm{L}$. Her renal function tests and electrolytes were normal.

Multiphasic computerised tomography abdomen showed mild splenomegaly, but no focal lesion in liver. Portal vein and splenic vein were dilated. Portal vein was $1.8 \mathrm{~cm}$ at porta hepatis. Left branch of portal vein appeared occluded. Right branch was dilated and tortuous and seen to drain into inferior vena cava via hepatic vein (Figure 1). Middle and left hepatic veins were normal.

Keywords: hepatic encephalopathy, portosystemic shunt, coil embolization Received: 29.9.2013; Accepted: 2.12.2013; Available online: 2.1.2014

Address for correspondence: Harikumar R. Nair, Consultant, Department of Gastroenterology \& Hepatology, Amrita Institute of Medical Sciences, Kochi, Kerala 682041, India. Tel.: +919995105881

E-mail: harikumnair@yahoo.co.in

Abbreviations: MELD: model for end stage liver disease

http://dx.doi.org/10.1016/j.jceh.2013.12.001
She was taken up for angioembolisation of the fistula. The right portal vein was percutaneously entered using Chiba needle and 6F sheath was introduced. Preliminary angiogram showed large venous sac communicating right anterior division of portal vein with right hepatic vein. Right posterior division was also seen to be communicating with the venous sac. Amplatz closure device was deployed to prevent distal migration of the coils (Figure 2 ) and after which multiple (12) $8 \mathrm{~mm} \times 8$ and $6 \times 6 \mathrm{~mm}(0.035)$ steel coils were deployed (Figure 3). Post-procedure, angiogram showed good result (Figure 4). Post-procedure period was uneventful and she had fall in arterial and serum ammonia levels. She had no further episodes of encephalopathy and was asymptomatic till 6 months of follow-up.

\section{DISCUSSION}

Our patient had multiple episodes of hepatic encephalopathy needing frequent hospitalizations, which was disproportionate to her Child-Pugh or model for end-stage liver disease score and had no obvious precipitating factors. Metabolic derangements in the setting of a progressively declining liver function are the usual setting for hepatic encephalopathy in liver cirrhosis. However in the presence of relatively well preserved liver function, a cirrhotic with marked portosystemic shunting and collateral circulation can develop hepatic encephalopathy. The usual clinical setting is that of recurrent episodes of hepatic encephalopathy in absence of usual precipitating factors. While the diagnosis can be established on real time sonography with color Doppler and cross sectional imaging like CT scan abdomen while angiography confirms the diagnosis; $3 \mathrm{D}$ ultrasound is a valuable adjunct tool. ${ }^{1}$ Intrahepatic PS shunts are rare and may be congenital or seen in the setting of cirrhosis with portal hypertension. ${ }^{2}$ The first description of congenital PS shunt was by Doehner et al. ${ }^{3}$

While majority of such episodes can be managed with usual medical measures, the frequent occurrence of such episodes especially without any precipitating factors 


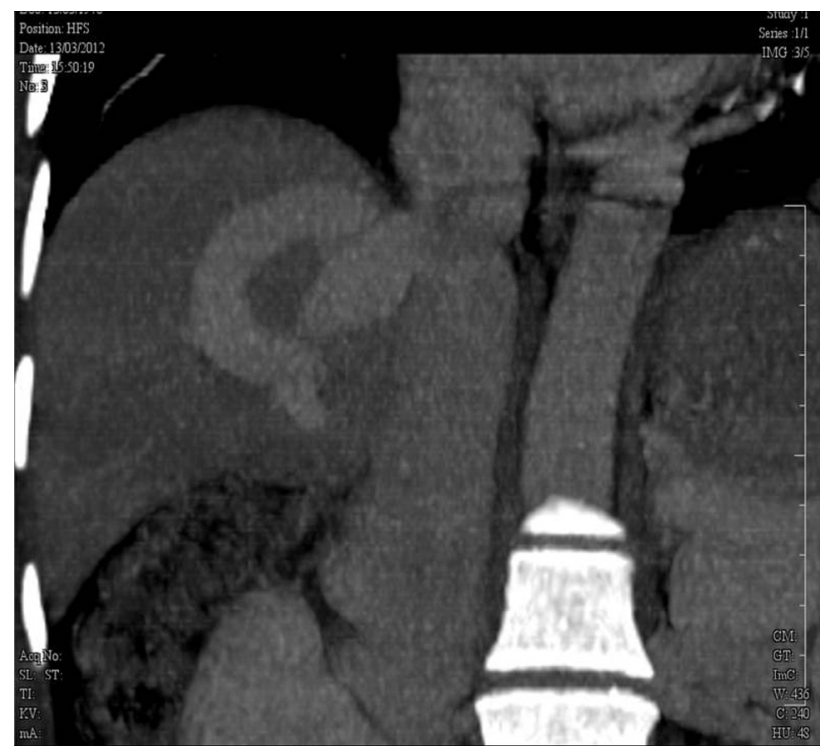

Figure 1 CT scan (coronal view) showing large intrahepatic portosystemic shunt.

resulting in significant disability of activities of daily living warrant deployment of invasive measures. Previous reports suggested use of surgical correction of PS shunts, which may be congenital or acquired. The first surgical correction of a congenital PS shunt was performed in 1982. Two years later, the first occlusion of a shunt was performed by interventional radiological technique.

Interventional radiological techniques are preferred now. There are several case reports and small series reported in the literature. The usual technique is embolisation using metal microcoils, although shunt can also be occluded by balloons or sclerosing agents. Gupta et al have reported successful treatment of congenital intrahe-



Figure 2 Amplatz device before deployment of steel coils.

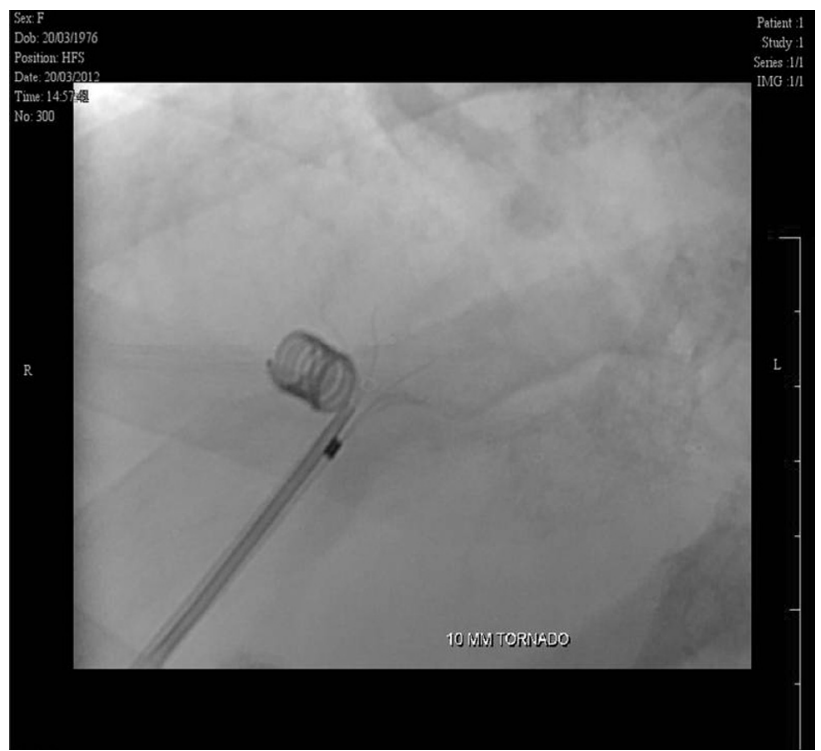

Figure 3 Steel coils being deployed.

patic portosystemic venous shunt with embolisation with n-butyl cyanoacrylate in a 14-month-male child. ${ }^{4}$ Lee et al demonstrated successful embolisation using the Amplatzer Vascular Plug II. ${ }^{5}$ Less frequently, such approaches may result in formation of ascites or new onset of varices. Hence, close clinical and endoscopic follow-up is warranted in post procedure follow-up. However, in a large multicentre European cohort study, Laleman et al found that there was no significant increase in de novo development or aggravation of preexisting varices, portal hypertensive gastropathy, or ascites. ${ }^{6}$ This study showed overall improvement in autonomy, decreased number of hospitalizations and, and severity of the worst HE episode in threequarters of the patients. Partial splenic embolisation has

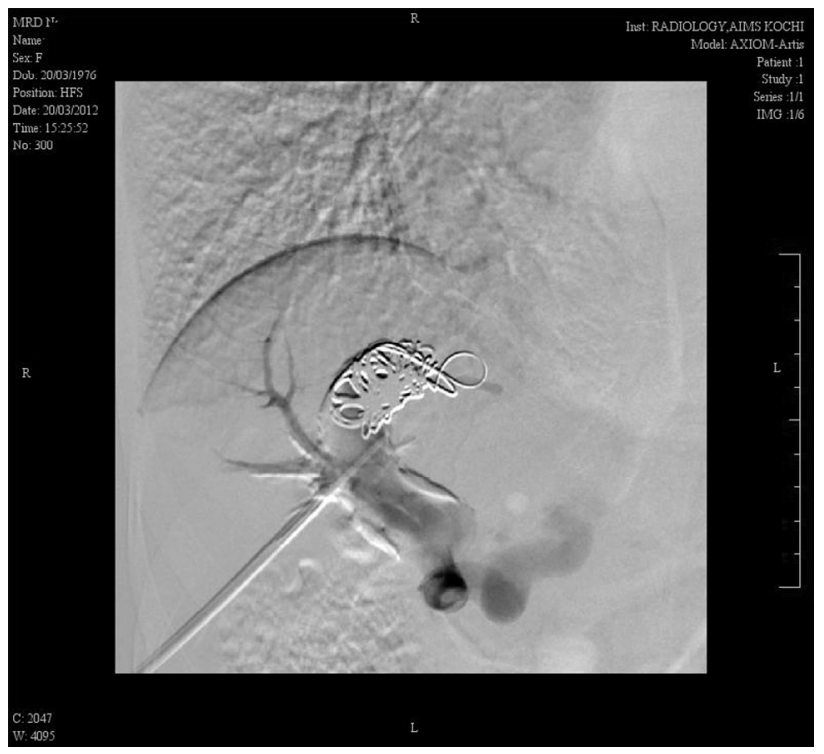

Figure 4 Angiogram after deployment of coils in the fistu. 
been suggested as additional treatment by some authors. ${ }^{7}$ Long-term follow-up reports confirm benefits of minimally invasive radiological techniques in the management of patients with recurrent hepatic encephalopathy who have responded poorly to medical management.

While it is generally believed that portosystemic shunts close once portal hypertension resolves after liver transplant, there are studies that suggest persistence of portal hypertension. Most of these studies were based on radiologic findings that were presumably subclinical. The natural history and significance of persistent shunting is unclear. However there are case reports of post liver transplant encephalopathy caused by persistent portosystemic shunts despite good graft function. ${ }^{8}$

\section{CONFLICTS OF INTEREST}

All authors have none to declare.

\section{REFERENCES}

1. Oguz B, Akata D, Balkanci F, Akhan O. Intrahepatic portosystemic venous shunt: diagnosis by colour/power Doppler imaging and three-dimensional ultrasound. British J Radiol. 2003;76:487490.

2. Mori H, Hayashi K, Fukuda T, et al. Intrahepatic portosystemic venous shunt: occurrence in patients with and without liver cirrhosis. AJR. 1987:149:711-717.

3. Doehner GA, Ruzicki Jr FF, Rousselot JM, Hoffman G. The portal venous system: on its pathological roentgen anatomy. Radiology. 1956;66:2016-2017.

4. Gupta V, Kalra N, Vyas S, Sodhi KS, Thapa BR, Khandelwal N. Embolization of congenital intrahepatic portosystemic shunt by n-butyl cyanoacrylate. Indian J Pediatr. 2009;76(10):1059-1060.

5. Lee $Y$, Shin BS, Lee JH, et al. Intrahepatic portosystemic venous shunt: successful embolization using the Amplatzer Vascular Plug II. Korean J Radiol. 2012;13:827-831.

6. Laleman W, Simon-Talero M, Maleux G, et al. Embolization of large spontaneous portosystemic shunts for refractory hepatic encephalopathy: a multicentre survey on safety and efficacy. Hepatology. 2013;57:2448-2457.

7. Mezawa S, Homma H, Akiyama T, et al. Selective embolisation of the splenic vein in patients with hepatic encephalopathy and splenorenal shunt. J Vasc Interv Radiol. 2004;15:1475-1481.

8. Barritt AS, Freid MW, Hayashi PH. Persistent portosystemic shunts after deceased donor liver transplant causing episodic hepatic encephalopathy despite good graft function. Dig Dis Sci. 2010;55(6):1794-1798. 